Review

\title{
Mass spectrometry in clinical chemistry: the case of newborn screening
}

\author{
Giancarlo la Marca* \\ Department of Neurosciences, Psychology, Pharmacology and Child Health, University of Florence, Newborn Screening, Biochemistry and Pharmacology \\ laboratory, Meyer Children's University Hospital, Florence, Italy
}

\section{A R T I C L E I N F O}

\section{Article history:}

Received 27 March 2014

Accepted 28 March 2014

Available online $\mathrm{xxx}$

\section{Keywords:}

Newborn screening

LC-MS/MS

Tandem mass spectrometry

Inborn errors of metabolism

Clinical chemistry

\begin{abstract}
A B S T R A C T
Newborn screening (NBS) program is a complex and organized system consisting of family and personnel education, biochemical tests, confirmatory biochemical and genetic tests, diagnosis, therapy, and patient follow up. The program identifies treatable metabolic disorders possibly when asymptomatic by using dried blood spot (DBS). During the last 20 years tandem mass spectrometry (TMS) has become the leading technology in NBS programs demonstrating to be versatile, sensitive and specific. There is consistent evidence of benefits from NBS for many disorders detected by TMS as well as for congenital hypothyroidism, cystic fibrosis, congenital adrenal hyperplasia by immune-enzymatic methods.

Real time PCR tests have more recently been proposed for the detection of some severe combined immunodeficiences (SCID) along with the use of TMS for ADA and PNP SCID; a first evaluation of their cost-benefit ratio is still ongoing. Avoiding false negative results by using specific biomarkers and reducing the false positive rate by using second tier tests, is fundamental for a successful NBS program. The fully integration of NBS and diagnostic laboratories with clinical service is crucial to have the best effectiveness in a comprehensive NBS system.
\end{abstract}

(C) 2014 Elsevier B.V. All rights reserved.

\section{Contents}

1. Introduction

2. Materials and methods

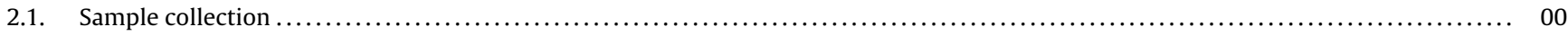

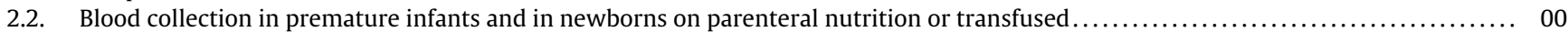

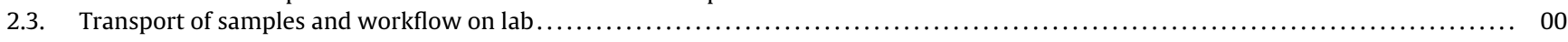

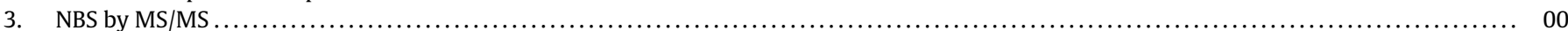

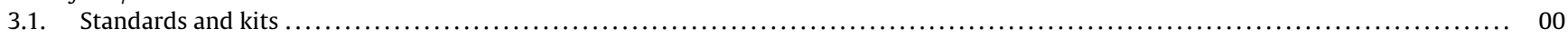

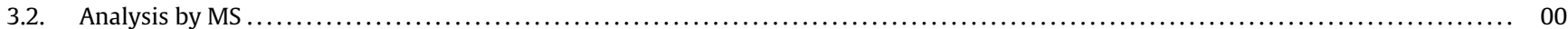

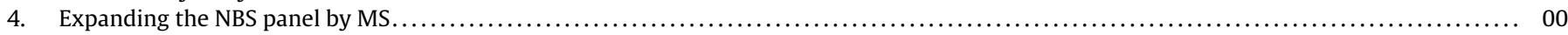

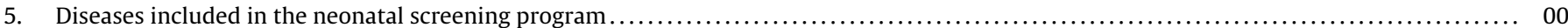

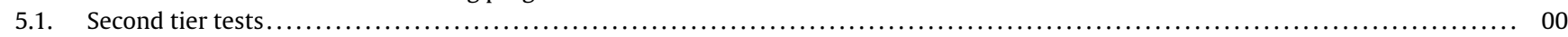

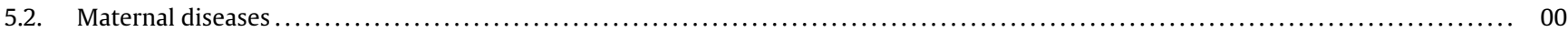

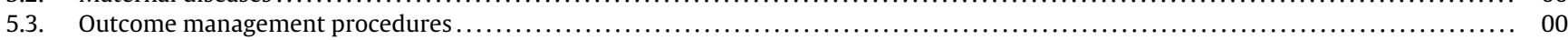

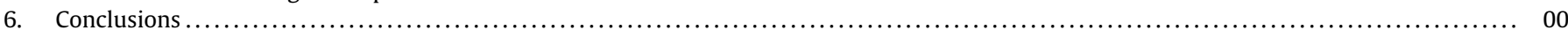

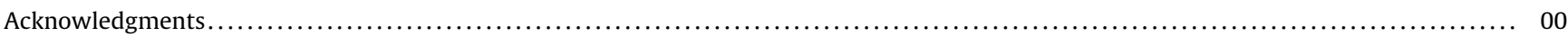

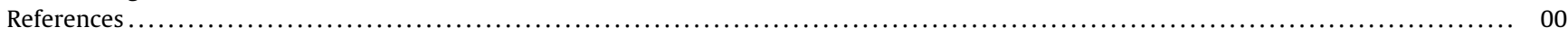

* Correspondence to: Department of Neurosciences, Psychology, Pharmacology and Child Health, University of Florence, Viale Pieraccini 6, 50139 Florence, Italy. Tel.: +39055 5662988; fax: +39055 5662489.

E-mail addresses: g.lamarca@meyer.it, giancarlo.lamarca@unifi.it 


\section{Introduction}

Newborn screening (NBS) is known to be a biochemical test enabling the identification of many inborn errors of metabolism (IEM) few days after birth. If they are not diagnosed and early treated, most of them can cause mental and/or growth retardation, severe permanent sequelae and in some case death. Considering that NBS requires expert lab technicians, chemists, biologists, nutritionists, medical specialists for metabolic disorders, it cannot be considered only an useful biochemical test, but it should be considered as a complex and integrated program. The objective of a newborn screening program is to detect some IEM before the clinical manifestation of the associated symptoms. As a consequence, medical doctors can start the best available treatment and have the best prognosis by modifying the natural course of the disease. The history of NBS as population-based test dates back from the beginning of 1960s when the microbiologist Robert Guthrie developed a simple and inexpensive bacterial inhibition assay (DBS based) able to identify the most frequent aminoacidopathia: the phenylketonuria [1]. In the following decade, some other clinical labs both in the United States and in Europe, added the congenital hypothyroidism $(\mathrm{CH})$ to their panel, again by using a single drop of whole blood on paper. The following development of electrospray tandem mass spectrometry in more recent years (1990s) has permitted the introduction of this new technology in clinical chemistry laboratories, in particular for newborn screening purposes [2]. MS/MS is a versatile, specific and sensitive technology giving technicians the possibility to measure many biomarkers in a single and fast analytical run. People working in newborn screening field understood the possibility to pass from one DBS for one test and one disorder to one DBS for one multiplex test for many disorders. In fact, today MS/MS can easily identify and quantify in a 2 or less minutes' run - several metabolites such as acylcarnitines, aminoacids, succinylacetone $[3,4]$ and more recently some purines [5-8]. Nowadays, including pilot projects regionally ruled and structured national NBS programs, many labs all around the world screen for more than 30 or more IEM with a single test. The number of potential identifiable disorders is not a technological hamper but it depends on regional or national public health strategies.

Some expanded newborn screening programs are now screening not only for $\mathrm{PKU}, \mathrm{CH}$, more recently for cystic fibrosis (CF), congenital adrenal hyperplasia $(\mathrm{CAH})$ and galactosemia, but also for others aminoacidopathias, beta oxidation fatty acid defects, organic acidurias, urea cycle defects and since 2011 for some severe combined immunodeficiences (SCID). One the fundamental worldwide-approved criterion is that one IEM can be screened only if a related treatment is available. For all disorders included in the newborn screening programs a therapy should be possible even if, in some cases, not completely curative. The term "not completely" is one relevant reason why newborn screening panels are not all the same worldwide.

The opinion of this writer is that even if a therapy is not completely curative, the early detection of the disorder and a following immediate correct treatment should give babies the possibility to have better quality of life, to extend life expectancy and when required, to allow a suitable genetic counseling (especially for future prenatal diagnoses). Moreover, an early diagnosis relieves families with a severe ill child from difficult diagnostic iter. These simple criteria represent the basal evaluation reported from Wilson and Jungner in 1963 to World Health Organization [9].

Therefore, the NBS cannot be considered only an efficient and isolated lab test of preventive medicine but it is a more integrated public health system involving many different categories such as lab technicians, chemists, biologists, biochemical geneticists (for both primary and confirmatory tests), administrative personnel, nurses, dieticians and/or pharmacologists, medical doctors expert in metabolic disorders and pediatricians. As consequence, only if laboratory NBS procedures, laboratory confirmatory procedures, clinical service and continue education are fully integrated, a real effectiveness of a NBS program will be reached.

\section{Materials and methods}

\subsection{Sample collection}

Blood samples were normally obtained by heel stick or handprick, spotted on filter paper (903, Whatmann, Milan, Italy or 226 grade paper, Ahlstrom, Helsinki, Finland) often referred as "Guthrie cards", dried at room temperature and sent daily by courier or mail to the newborn screening laboratory. In most part of European countries as well as in the USA and Australia a formal guideline for the sampling procedure is available. In about half the countries these guidelines have been developed by health authorities and in the other half by professional groups, either locally or nationally.

The number of drops is variable (minimum 3-4, maximum 12) and it is generally depending on the number of tests (both first and second tier tests).

The expansion of blood on the paper depends on haematocrit level and drying conditions.

Blood collection for newborn screening in Italy (as in most part of countries) is recommended between 48 and $72 \mathrm{~h}$ of life. In Europe, the collection ranges from the $36 \mathrm{~h}$ in Austria and Croatia to $168 \mathrm{~h}$ of Greece, Netherlands and Luxembourg [10]. Timing of the collection is a critical issue because marker levels could vary physiologically in the neonatal period [11].

In some countries, such as Finland and Malta, cord blood sampling is used for newborn screening testing according to early maternal and newborn discharge [12,13], but it has been evaluated that better results are obtained from samples collected by heel/hand prick at a later stage [14,15].

Use of urine collected onto an absorbent paper placed in the baby's nappy could be a very useful tool as additional but not alternative NBS test. Even if not common, some NBS programs continued the practice of urine screening [16] and in some cases the urine DBS has significantly contributed to the IEM detection up to $44 \%$ of total cases [17].

An important parameter for the quality of the program is the completeness of sampling, preferably $100 \%$ but reaching this value is practically impossible because in most countries it should be possible for parents to refuse participation of their children to NBS programs. If informed consent is taken seriously, the option to stay out will sometimes take place.

\subsection{Blood collection in premature infants and in newborns on parenteral nutrition or transfused}

Prematurity, birth weight, parenteral nutrition, transfusions and type of feeds can all potentially influence NBS results.

In order to decrease parental stress related to retesting and to ensure that important information for interpreting screening results is given, established protocols are useful. These protocols should provide repeated tests during the early postnatal period for infant requiring blood/plasma transfusion, for premature babies or term/preterm babies on parenteral nutrition at the time of screening sample collection.

In some countries $[18,19]$ for premature infants (birth weight $<1800 \mathrm{~g}$ ), the first DBS sample is collected on the 3rd-5th day of life, then two additional samples at 15 and 30 days. For babies on parenteral nutrition, including premature babies, a second sample at $48 \mathrm{~h}$ after the ending of parenteral nutrition is collected. In all 
transfused newborns, a new sample is taken between 7 and 15 days after the end of transfusion.

\subsection{Transport of samples and workflow on lab}

Some markers are relatively unstable and heat, humidity and delays in transport can cause degradation and potential false negatives results. Therefore, when mail service is not efficient, the samples should be sent to the lab by courier.

For the same reason the best practical workflow is seven days/week and $24 \mathrm{~h}$ /day but it is quite rare. A typical laboratory activity is 5/6 days per week and $12 \mathrm{~h}$ based shift works.

Test turnaround time within the laboratory should be kept short; a maximum of $48 \mathrm{~h}$ is recommended.

\section{NBS by MS/MS}

\subsection{Standards and kits}

Labeled internal standards of acylcarnitines and amino acids are available from different manufactures like Cambridge Isotope Laboratories, Andover, MA, USA; a typical stock solution is prepared in methanol. The standard concentrations may vary but normally it is in the range $500-2500 \mu \mathrm{mol} / \mathrm{L}$ for amino acids, and 7.6-152 $\mu \mathrm{mol} / \mathrm{L}$ for acylcarnitines. All chemicals and solvents must be of the highest purity available from commercial sources and they are normally used without any further purification. Some laboratories use commercially IVD kits such as NeoGram ${ }^{\circledR} /$ NeoBase $^{\circledR}$ from Perkin Elmer (Waltham, MA, USA) and MassChrom ${ }^{\circledR}$ from Chromsystems (Munich, Germany). It is important to highlight that "use of certified kit material" does not mean that a mass spectrometer can be used without any knowledge or specific education, especially for newborn screening or diagnostic tests. A mass spectrometer is not a common bench top machine normally used in a general laboratory or a "black box". Training and education in mass spectrometry for newborn screening lab people is a fundamental issue, it cannot be delayed and it cannot be overruled by using certified kit material.

\subsection{Analysis by $M S$}

Screening analyses is worldwide performed according to the conventional method as previously reported $[2,20]$ with some modifications.

Originally, it was found that carnitine and acylcarnitines were easily measured from plasma samples by fast atom bombardment or thermospray $[21,22]$ for the detection of fatty acid disorders.

Later on, advancements in MS/MS and research demonstrated that the analysis of acylcarnitines could be used to identify fatty acid oxidation defects in a neonatal population. Carnitine and its esters were perfect candidates for a MS/MS screening technique since they all presented a common product ion. Regardless of the attached fatty acid ester, a common fragment (85 Th) that contains the quaternary ammonium function could be detected with high sensitivity and specificity (Fig. 1). These structural characteristics enabled the detection of a panel of saturated, unsaturated and hydroxylate acylcarnitines in an easy and cheap way.

The addition of aminoacids to newborn screening panel dates back to the beginning of nineties' with the first endeavor to measure phenylalanine using fast atom bombardment (FAB) [20]. The procedure required esterification (as butyl esters) to enhance surface ionization in a glycerol matrix. The butylation "quenched" the negative charge on the acid moiety of phenylalanine increasing ionization efficiency and sensitivity.

In a first stage, methyl esterification was used previously for analysis of acylcarnitines in plasma [23] but later on the most part of laboratories switched off to butylation.
During the first tests by using phenylalanine butyl ester for the detection of PKU other aminoacids were identified, deducing that a common neutral product, butylformate presenting with a mass of $102 \mathrm{Da}$. Since then, the common neutral loss of $102 \mathrm{Da}$ is the basis for the MS/MS assay of several key amino acids in newborn screening (Fig. 1) [24].

While butyl esterification assays become routine, in the last ten years new methods were developed able to detect AAs and ACs as their native free acids (underivatized) to simplify analytical operations and to minimize the use of corrosive compounds.

The collision induced dissociation of amino acids and acylcarnitines as butyl esters and free acids is reported in Fig. 1.

Nowadays classical routine MS/MS analysis is performed on one/two (depending on the number of the samples) instruments normally triple quadrupoles and one additional for back-up. Quantitation is performed by using the "isotopic dilution" technique. The analyte concentrations are calculated automatically using property software. Tuscany regions as an example use ABI Sciex (API 4000, 3200 (AB Sciex, Foster City, CA, USA)) or Shimadzu (8040, Kyoto, Japan) LC-MS/MS systems and Chemoview (AB Sciex, Foster City, CA, USA) or Neonatal Solution (Shimadzu, Kyoto, Japan). Other similar and equally efficient systems are commercially available.

\section{Expanding the NBS panel by MS}

New methods are now available and they supplement the current screening panel. The classical underivatized and derivatized sample preparation procedures were further modified to quantify succinylacetone (specific marker for tyrosinaemia type I) by adding a new component: hydrazine or its derivatives. The sample preparation can be performed including the extraction of succinylacetone as hydrazone derivative, along with other metabolites in a single step since 2008 [3]. Later on alternative methods requiring two different extraction procedures [4] and cleaning steps [25] have been developed.

In 2011 and 2014 two new cheap methods able to quantify some purines along with other metabolites have been developed $[5,26]$. The measurements of these new metabolites via underivatized method, allow the detection of adenosine deaminase (ADA) and purine nucleoside phosphorylase (PNP) deficiencies at birth. Some widely used sample preparation procedures are described in Fig. 2.

ADA and PNP are fatal autosomal recessive forms of SCID caused by an inherited disorder of purine metabolism. Both ADA and PNP-SCID comply with all the criteria for inclusion in a newborn screening program. The Secretary's Advisory Committee on Heritable Disorders in Newborns and Children in 2010 and the European EU tender in 2011 recommend the inclusion of all SCIDs in the newborn screening panels. Since 2008 a polymerase chain reaction (PCR) based test is available for the detection of all T-SCID. This method presents the indubitable advantage to screen for all the T-SCID panel but it is quite expensive (RT-PCR machines, kits and molecular biologists are needed) with respect to MS; moreover it has been recently demonstrated that it is not sensitive for late/delayed ADA-SCID forms and that it can detect some disorders not responding to the futures to be included in a NS panel $[6,27,28]$.

Some methods were developed for the detection of lysosomal storage disorders (LSDs) and even if for some of them a reliable and relatively simple test is available, a reasonable associated therapy could be still not available [29-38]. It is not the task of this writer to produce a statement that the LSDs should be included in newborn screening panels, but some of these disorders seem to meet the criteria for inclusion, including basal availability of a simple test, a combination therapy that modifies 
BUTYLATED<smiles>[R]C([NH3+])C(=O)OCCCC</smiles><smiles>[R]C=[N+]=[N-]</smiles>

UNBUTYLATED<smiles>[R]C([NH3+])C(=O)O</smiles>

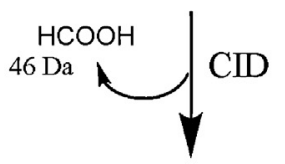<smiles>[R]C=[N+]=[N-]</smiles>

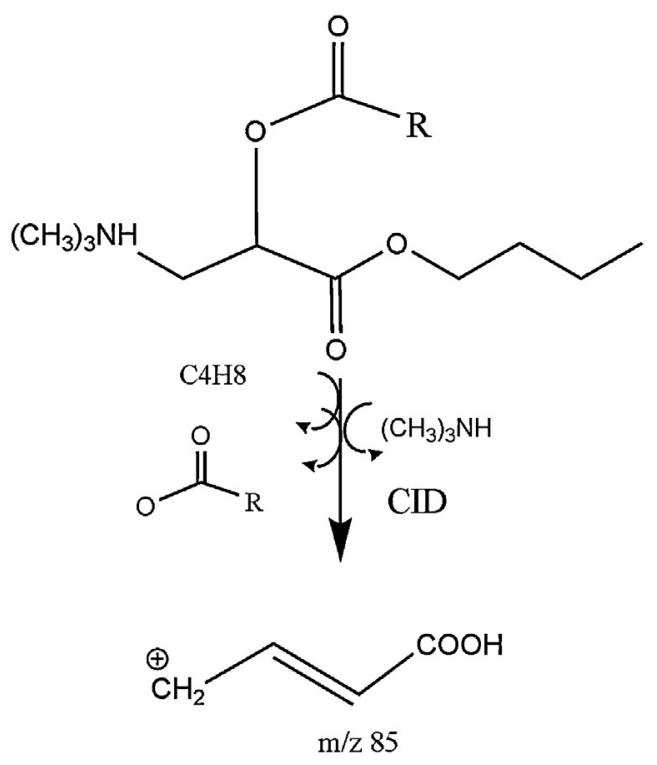

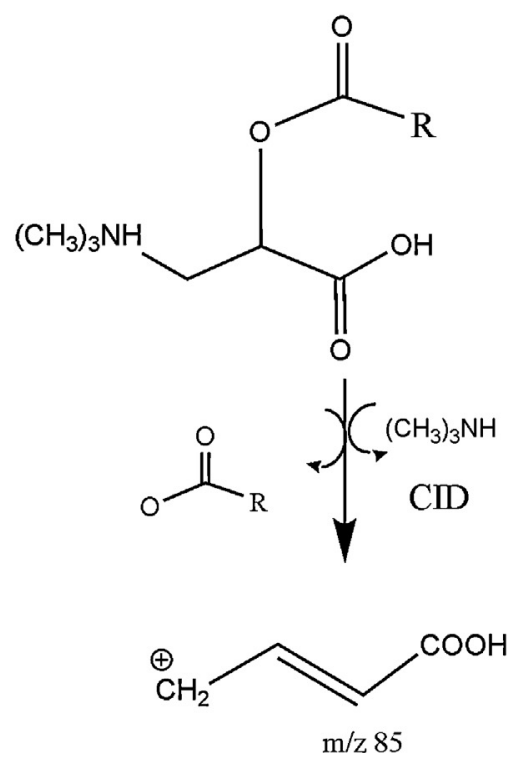

ACYLCARNITINE

Fig. 1. Schematic representation of fragmentation in MSMS of butylated and unbutylated acylcarnitine (panel A) and amino acid residues (panel B).

the natural course of the disease, early diagnosis that allows genetic counseling and prenatal diagnosis in families with an affected baby.

\section{Diseases included in the neonatal screening program}

The panel used for neonatal screening is different from region to region and from country to country.

The American College for Medical Genetics in the 2012 decided for a national and common NBS panel for the USA newborns. It contains 55 disorders (including tests by immune-enzymatic systems): 30 IEM for the named core panel and 25 as secondary target.

A national screening program does not exist in Canada. Health care and screening programs fall under provincial and territorial jurisdiction. There is a wide spectrum in the number of disorders for which screening is offered, ranging from 5 disorders to 38, depending on the jurisdiction. The Australian Newborn Screening Policy and Guidelines Document in 2011 reported on 25 disorders detected by means of NS (even if "other disorders could be detected during the test, including maternal disorders"). In Japan, where a national pilot project is finished in 2012, the beginning of a national NS program by MS will start the next April 2014. The European situation is the more complicated and even if common recommendations are available, many relevant differences are still present. The most relevant differences are the time of the drawing of the blood period (between 36 and $168 \mathrm{~h}$ after birth), the number of newborn screening centers per country ranging from 1 to more than 
A)

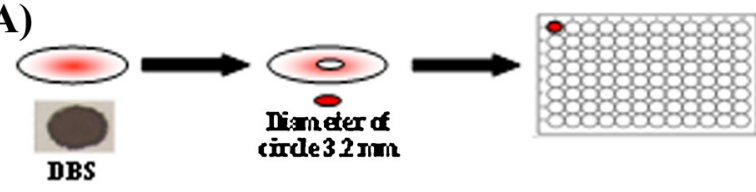

$200 \mu \mathrm{L}$ of $\mathrm{HeOH}+$ labelled intemal standards

$+\quad+100 \mu \mathrm{r}$ hydrasine 3mmollL + Purine IS orty in line 2

Incubation of $25 \mathrm{~min}$ at $37^{\circ} \mathrm{C}$

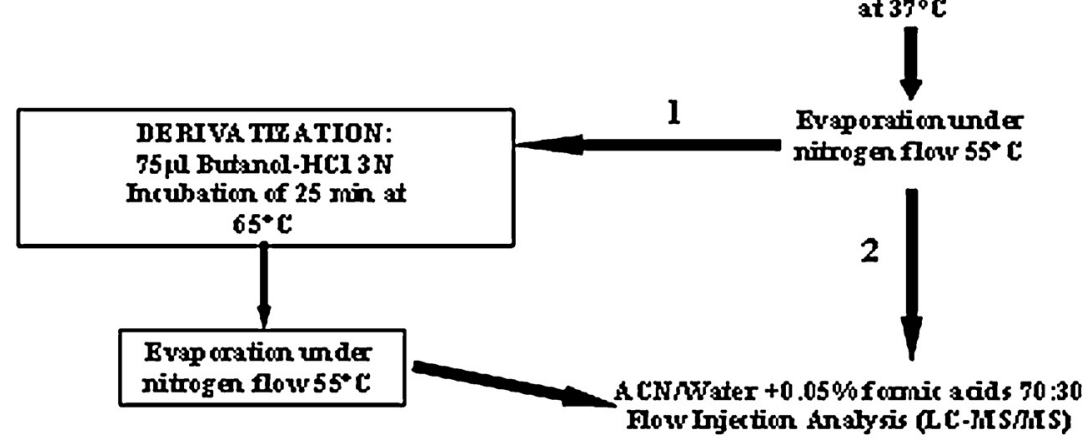

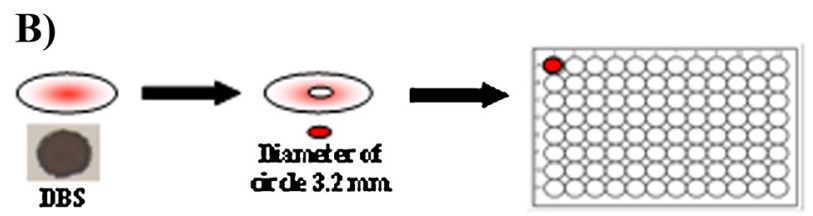

Reilualblood pot

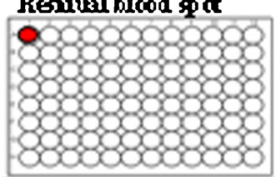

$200 \mu$ of MeOH+ balled IS

Derivatication:

$75 \mu \mathrm{LButanolHC13N}$ at $65^{\circ} \mathrm{C}$ for $25 \mathrm{~min}$

$100 \mu \mathrm{L}$ of

hydraxine 3nunllL + Suar Is

+ Pumine IS

Incubation: at $37^{\circ} \mathrm{C}$ for $25 \mathrm{~mm}$
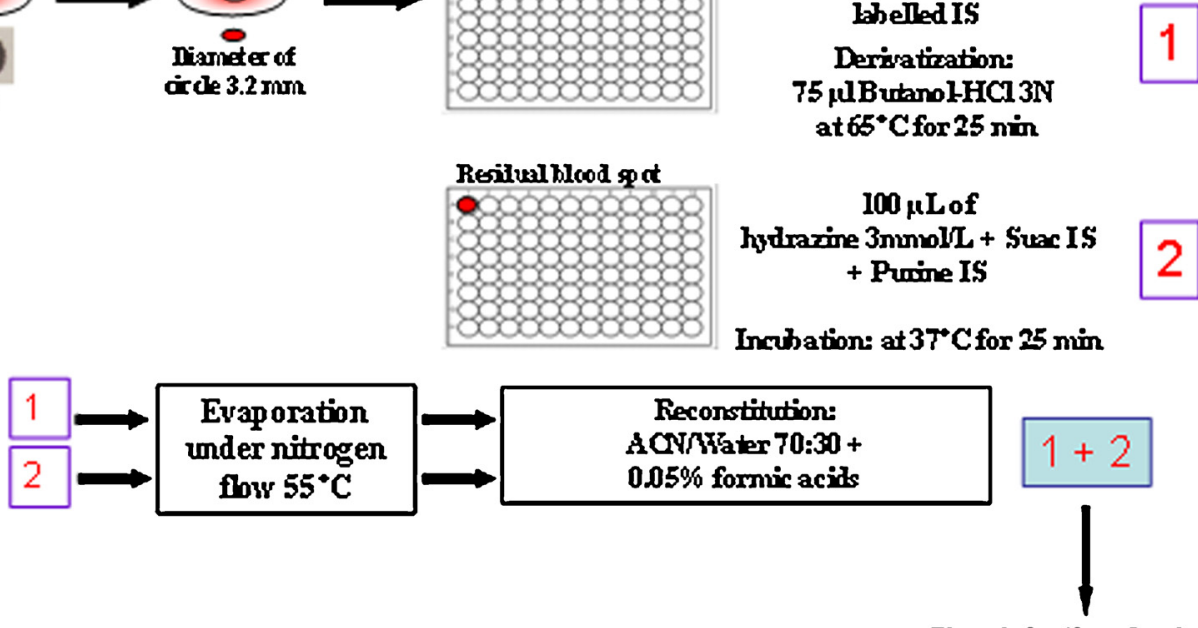

Flowinjection Anabrsis

(LCMSIMS)

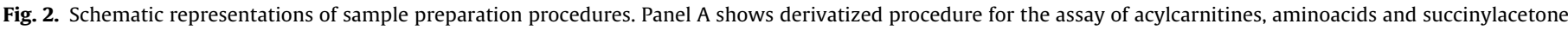

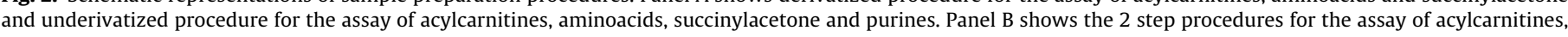
aminoacids as butyl esters and succinylacetone and purines in naïve forms

20. Moreover and probably mostly important a common NS panel does not exist due to public health systems falling under regional jurisdictions.

In Italy the expanded NBS by MS is regionally ruled even if a national law has been promulgated at the end of December 2013. A national expert commission is now evaluating the disease panel and the minimal number of newborn screening centers.

Table 1 lists the suspected disease included in Tuscany region NBS panel in the presence of one or more changes, the cutoff values and the ratios for each analyte. Twenty-four disorders consist of primary panel, 22 secondary panel. Some diseases identifiable by expanded newborn screening have been included in the panel as conditions that are part of the differential diagnosis of a primary panel condition, such as IBD defect versus SCAD deficiency. Formiminoglutamic aciduria, which may appear as a false butyrrylcarnitine (C4) alteration [39] by using derivatized sample preparation procedures, is no longer subject to recall because it is considered a benign condition. Some authors have considered retaining 3-methyl-crotonylglycinuria in the screening panel, despite it being considered a biochemical condition rather than a disease $[40,41]$. Recently some authors reported data confirming that MCC deficiency, despite low penetrance, may lead to a severe clinical phenotype resembling classical organic acidurias [42].

Some authors believe it may be relevant to maintain glycine in the screening panel because it is a secondary marker in some organic acidaemias [43]. Moreover, even if only in some cases [44], glycine could permit the diagnosis of nonketotic hyperglycinaemia [45] which, although the disease is currently not treatable, allows appropriate genetic counseling and possible prenatal diagnosis.

Tyrosine is an analyte frequently responsible for large number of recalls. Tyrosine can be elevated in tyrosinaemia types I, II and III, but it also can be transiently increased in many newborns, especially those born prematurely. In the case of tyrosinaemia type I, false-negatives may occur if the cut-off is too high or if the 
Table 1

Conditions tested in the Tuscany/Umbria newborn screening program, primary and secondary related biomarkers, and used ratios.

\begin{tabular}{|c|c|c|c|c|}
\hline Disorders & $\begin{array}{l}\text { Primary markers } \\
\text { (cutoff } \mu \mathrm{mol} / \mathrm{L} \text { ) }\end{array}$ & $\begin{array}{l}\text { Secondary markers } \\
\text { (cutoff } \mu \mathrm{mol} / \mathrm{L} \text { ) }\end{array}$ & Ratios & Diagnoses \\
\hline \multicolumn{5}{|l|}{ Core panel } \\
\hline Classic PKU & Phe $\uparrow($ n.v. <100) & 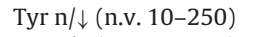 & Phe/Tyr & 18 \\
\hline HPA type II and III & Phe $\uparrow($ n.v. $<100)$ & 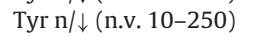 & Phe/Tyr & 47 \\
\hline Tyrosinemia type I & $\mathrm{SA} \uparrow($ n.v. $<2)$ & Tyr n/ $\uparrow($ n.v. $10-250)$ & & 3 \\
\hline Citrullinemia type I & Cit $\uparrow($ n.v. 3-30) & & & 7 \\
\hline Argininosuccinic aciduria & $\operatorname{Asa} \uparrow($ n.v. $<1)$ & Cit $\uparrow($ n.v. 3-30) & & 2 \\
\hline Homocystinuria (cystathionine $\beta$ synthase deficiency) & $\operatorname{Met} \uparrow($ n.v. 6-36) & & & \\
\hline Maple syrup urine disease & $\begin{array}{l}\text { Val } \uparrow(\text { n.v. <170); } \\
\text { Ile } / \text { Leu } \uparrow(\text { n.v. <237) }\end{array}$ & & & \\
\hline Propionic acidaemia & $\mathrm{C} 3 \uparrow($ n.v. $<3.3)$ & Gly $\uparrow($ n.v. <260) & $\mathrm{C} 3 / \mathrm{CO} ; \mathrm{C} 3 / \mathrm{C} 4 ; \mathrm{C} 3 / \mathrm{C} 16$ & 3 \\
\hline Metylmalonic aciduria mut & C $3 \uparrow($ n.v. $<3.3)$ & Gly $\uparrow($ n.v. <260) & $\mathrm{C} 3 / \mathrm{CO} ; \mathrm{C} 3 / \mathrm{C} 4 ; \mathrm{C} 3 / \mathrm{C} 16$ & 8 \\
\hline Metylmalonic aciduria $\mathrm{Cbl} \mathrm{A}$ and $\mathrm{B}$ & $\mathrm{C} 3 \uparrow($ n.v. $<3.3)$ & Gly $\uparrow($ n.v. <260) & $\mathrm{C} 3 / \mathrm{CO} ; \mathrm{C} 3 / \mathrm{C} 4 ; \mathrm{C} 3 / \mathrm{C} 16$ & \\
\hline Isovaleric acidemia & C5 $\uparrow($ n.v. $<0.56)$ & & $\mathrm{C} 5 / \mathrm{C} 3 ; \mathrm{C} 5 / \mathrm{C} 4 ; \mathrm{C} 5 / \mathrm{C} 8$ & 3 \\
\hline Multiple carboxylase deficiency & $\mathrm{C} 5 \mathrm{OH} \uparrow($ n.v. $<0.7)$ & C3 n/ (n.v.<3.3) & & \\
\hline 3-Methylcrotonylglycinuria & $\mathrm{C} 5 \mathrm{OH} \uparrow(\mathrm{n} . \mathrm{v} .<0.57)$ & & & $\begin{array}{l}6 \\
4 \text { maternal }\end{array}$ \\
\hline Glutaric acidemia type I & C5DC $\uparrow($ n.v. $<0.18)$ & & $\begin{array}{l}\text { C5DC/C4; C5DC/C8; } \\
\text { C5DC/C } 12 ; C 5 D C / C 3 D C\end{array}$ & 2 \\
\hline 3-OH-3 methylglutaryl-CoA lyase deficiency & $\mathrm{C} 5 \mathrm{OH} \uparrow($ n.v. $<0.57)$ & C6DC n/个 (n.v.<0.7) & & \\
\hline$\beta$ Ketothiolase deficiency & C5: $1 \uparrow($ n.v. $<0.06)$ & $\mathrm{C} 5 \mathrm{OH} \mathrm{n} / \uparrow($ n.v. $<0.57)$ & & 1 \\
\hline Primary carnitine deficiency & CO $\downarrow$ (n.v. $5.5-45)$ & Ctot $\downarrow$ (v.n. 21-73) & & $\begin{array}{l}2 \\
2 \text { maternal }\end{array}$ \\
\hline Medium chain acyl-CoA dehydrogenase deficiency & $\begin{array}{l}\mathrm{C} 6 \uparrow(\text { n.v. }<0.25) ; C 8 \uparrow \\
(\text { n.v. }<0.40) ; C 10: 1 \uparrow \\
(\text { n.v. }<0.5)\end{array}$ & $\mathrm{C} 10 \uparrow($ n.v. $<0.36)$ & $\mathrm{C} 6 / \mathrm{C} 8 \uparrow ; \mathrm{C} 8 / \mathrm{C} 10 \uparrow$ & 16 \\
\hline Very long-chain acyl-CoA dehydrogenase deficiency & $\mathrm{C} 14: 1 \uparrow(\mathrm{n} . \mathrm{v} .<0.44)$ & $\begin{array}{l}\mathrm{C} 14 \mathrm{n} / \uparrow(\text { n.v. }<0.57 \\
\mathrm{C} 16 \mathrm{n} / \uparrow(\text { n.v. } 0.48-5.6) \\
\mathrm{C} 18: 1 \mathrm{n} / \uparrow(0.39-2.43)\end{array}$ & $\begin{array}{l}\text { C14:1/C4; C14:1/C5; } \\
\text { C14:1/C8 }\end{array}$ & 6 \\
\hline Long-chain hydroxyacyl-CoA dehydrogenase deficiency & $\begin{array}{l}\mathrm{C} 16-\mathrm{OH} \uparrow(\text { n.v. }<0.1) ; \\
\mathrm{C} 18: 10 \mathrm{OH} \uparrow(\text { n.v. }<0.05)\end{array}$ & & & 1 \\
\hline Trifunctional protein deficiency & $\begin{array}{l}\mathrm{C} 16-\mathrm{OH} \uparrow(\text { n.v. }<0.1) \\
\mathrm{C} 18: 1 \mathrm{OH} \uparrow(\text { n.v. }<0.05)\end{array}$ & & & 1 \\
\hline Adenosine deaminase deficiency & $\begin{array}{l}\text { Ado } \uparrow(\text { n.v. }<2) \\
\text { Deoxyado } \uparrow(\text { n.v. }<0.1)\end{array}$ & & & 1 \\
\hline \multicolumn{5}{|l|}{ Secondary targets } \\
\hline Tyrosinemia type II and III & $\operatorname{Tyr} \uparrow($ n.v. $<250)$ & & & \\
\hline Citrullinemia type II & Cit $\uparrow($ n.v. 3-30) & & & 2 \\
\hline Argininemia & $\operatorname{Arg} \uparrow($ n.v. $<34)$ & & & \\
\hline BH4 defects & Phe $\uparrow($ n.v. <100) & 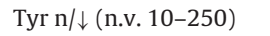 & Phe/Tyr & 1 \\
\hline MTHFR deficiency & Met $\downarrow$ (n.v. 6-36) & & & \\
\hline Methionine adenosyl transferase deficiency & Met $\uparrow($ n.v. 6-36) & & & 2 \\
\hline Metylmalonic aciduria Cbl C and D & $\mathrm{C} 3 \uparrow($ n.v. $<3.3)$ & $\begin{array}{l}\text { Met } \uparrow(\text { n.v. }<6) \\
\text { C16:10H } \uparrow(\text { n.v. }<0.09)\end{array}$ & $\mathrm{C} 3 / \mathrm{CO} ; \mathrm{C} 3 / \mathrm{C} 4 ; \mathrm{C} 3 / \mathrm{C} 16$ & $\begin{array}{l}14 \\
19 \text { maternal }\end{array}$ \\
\hline Malonic Aciduria & C3DC $\uparrow($ n.v. $<0.7)$ & & & \\
\hline 2-Methyl 3-OH-butyryl-CoA dehydrogenase deficiency & $\mathrm{C} 5 \mathrm{OH} \uparrow($ n.v. $<0.57)$ & & & \\
\hline Short chain acyl-CoA dehydrogenase deficiency & C $4 \uparrow($ n.v. $<0.92)$ & & & 10 \\
\hline Glutaric acidemia type II (MAD) & $\mathrm{C} 4-\mathrm{C} 18 \uparrow$ & & & \\
\hline Short hydroxyl acyl-CoA dehydrogenase deficiency & $\mathrm{C} 4 \mathrm{OH} \uparrow($ n.v. $<0.50)$ & & & \\
\hline 3-Methylglutaconyl-CoA hydratase deficiency & $\mathrm{C} 5 \mathrm{OH} \uparrow($ n.v. $<0.57)$ & & & 1 \\
\hline Isobutyryl-CoA dehydrogenase deficiency & C4 $\uparrow($ n.v. $<0.92)$ & & & 14 \\
\hline Carnitine acylcarnityne translocase deficiency & C16个 (n.v. $0.48-5.6)$ & & & \\
\hline Carnitine palmitoyl transferase II deficiency & $\begin{array}{l}\mathrm{C} 16 \uparrow \text { (n.v. } 0.48-5.6) \\
\mathrm{C} 18: 1 \uparrow(\text { n.v. } 0.39-2.43)\end{array}$ & $\mathrm{C} 2 \downarrow($ n.v. $6.3-48)$ & $\begin{array}{l}(\mathrm{C} 16+\mathrm{C} 18: 1) / \mathrm{C} 2 \\
\text { within } 10 \text { days of life }\end{array}$ & \\
\hline Carnitine palmitoyl transferase I deficiency & 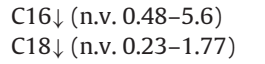 & $\mathrm{C} 0 \mathrm{n} / \uparrow(8-45)$ & $\begin{array}{l}\mathrm{C} 0 /(\mathrm{C} 16+\mathrm{C} 18) \text { within } \\
10 \text { days of life }\end{array}$ & \\
\hline HHH syndrome & Orn $\uparrow($ n.v. 25-150) & & & \\
\hline Gyrate atrophy of the choroids and retina & Orn $\uparrow($ n.v. 25-150) & & & \\
\hline Purine nucleoside phosphorylase deficiency & $\begin{array}{l}\text { Deoxyguanosine } \uparrow \\
(\text { n.v. }<0.09) \\
\text { Deoxyinosine } \uparrow \\
(\text { n.v. }<2.85)\end{array}$ & $\begin{array}{l}\text { Guanosine } \uparrow(\text { n.v. }<1.7) \\
\text { Inosine } \uparrow(\text { n.v. }<33)\end{array}$ & & \\
\hline
\end{tabular}

screening is performed in the first 2-5 days of life. However, the use of a low cut-off level increases the false-positive rate. In recent years, the use of succinylacetone as new biomarker has allowed people working in NS field to avoid false-negative results for tyrosinaemia type I.

Attention should be paid to the higher cut-off of citrulline, capable of diagnosing citrullinaemia types I and II, and, as second marker, argininosuccinic aciduria. We should also to evaluate the citrulline lower cut-off as a possible sign of defects in the first and second steps of the urea cycle as well as mitochondrial diseases such as NARP.

\subsection{Second tier tests}

Some important metabolites in expanded newborn screening programs, markers of diseases, have proven to have poor 


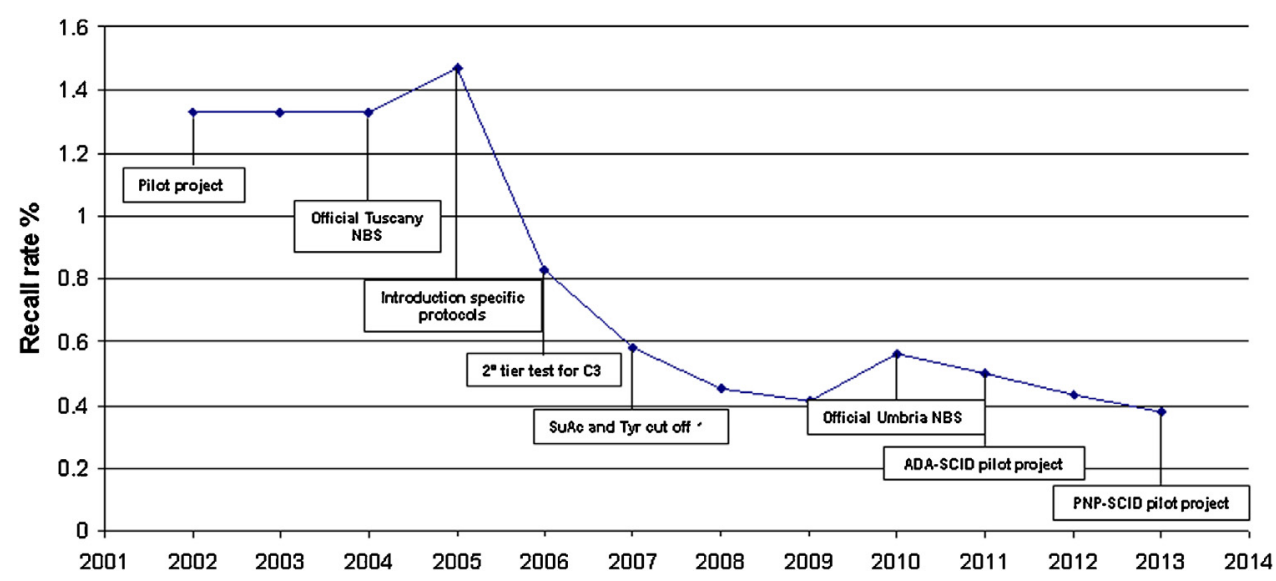

Fig. 3. Recall rate of expanded newborn screening in Tuscany, 2002-2013.

specificity, causing a critical impact on the population due to the high number of recalls. The best way to decrease the recall rate, due to false positive results in the primary screening test, is represented by the introduction of the second tier test, performed on the same NBS specimen with no necessity to additionally contact patient' family. Second tier test result overrules the primary result.

Since for some metabolites there is an overlap between controls and patients ranges, second tier test proved its superiority in discriminating the two populations thanks to the high specificity.

The choice of reference values for NBS test should be a good compromise between sensitivity and specificity; a good sensitivity could result in a high false positive rate while having high specificity could cause false negative results. Adjusting cutoff values for each metabolite should consider the availability of a second tier test; if it is available, primary test cut-off should be reduced to capture presumptive positive cases [46].

Second tier tests are usually performed by HPLC-MS/MS but in recent years a second tier genetic testing could be used to detect cystic fibrosis [47]. For CAH screening, the primary test is performed by immunoassay and positive results are retested by HPLC-MS/MS to obtain a more specific and detailed steroid profile [48].

Some authors reported about the use of succinylacetone only as second tier test to improve the relatively poor specificity of the primary screening using tyrosine $[49,50]$.

In 2011 in Tuscany region, ADA SCID biomarkers were included in the panel of expanded NBS; also in this case a second tier test can be performed when elevated concentration of purines metabolites are detected [51].

However second tier test usually identify additional analytes, not detectable at the primary NBS test, for better interpretation of abnormal findings.

This kind of approach is well represented by propionylcarnitine (C3), primary marker for methylmalonic acidurias (MMA) and propionic acidurias (PA). In a retrospective study our group showed that on 564 total recalls, 124 (22\%) were for C3 of whom only 5 (4\%) were truly affected: 3 methylmalonic acidurias and 2 PAs. The development of a second tier test to detect free diagnostic acids allowed to distinguishing true positives from false positives rising the positive predictive value for C3 to $100 \%$ [51].

The introduction of second-tier tests proved to be an excellent strategy to cope with false positive problem. For this reason, to date, an increasing number of publications relate to the development of second-tier test is reported [52-56].
Fig. 3 illustrates the recall rate trend from 2002 to February 2014 in Tuscany. At the beginning, during the pilot project, cut-offs of mean \pm 2 SD for all analytes were established. Recall rate increased in 2004 with the increase in the number of analytes considered. Cut-off values were modified for specific analytes, up to 4.5 SD to minimize the frequency of false-positive results. Adjustment of cutoffs, the introduction of specific ratios, the use of the "post analytical tools" of R4S collaborative project and the development of some second-tier test allowed a reduction in the recall rate in recent years from $1.47 \%$ to $0.3 \%$ ). The positive predictive value increased from $3.5 \%$ in 2004 up to $19.4 \%$ in 2013 .

\subsection{Maternal diseases}

In some newborns, screening results can be falsely positive for maternal defects, resulting in transplacental passage of metabolites. In our experience, out of 400000 babies, we observed low values of $\mathrm{C} 0, \mathrm{C} 2$ and total carnitines associated with a maternal primary carnitine defect; two twins with high values of $\mathrm{C} 5 \mathrm{OH}$ with an asymptomatic mother affected by 3-methylcrotonylglycinuria; an infant with high C3 and methylmalonic acid detected by secondtier testing with a mother with a defect of gastrin; and two infants with elevated levels of phenylalanine with a mother affected by undiagnosed mild hyperphenylalaninaemia.

\subsection{Outcome management procedures}

When a positive screening (first screening and second tier test, if available) result occurs, two different subsequent procedures are followed:

(a) In the case of disorders that are at risk of acute metabolic decompensation during the neonatal period, a metabolic specialist immediately recalls the baby; clinical examinations, confirmatory tests, including plasma amino acid, plasma acylcarnitine and urine organic acid profiles are performed;

(b) In the case of all other disorders, the nursery is contacted to provide for a second dried blood spot. If the repeated test shows a positive result, clinical examinations and confirmatory tests are performed (see Fig. 4).

In both cases, if results from the confirmatory tests are positive, the metabolic clinicians provide management, counseling and follow-up. 


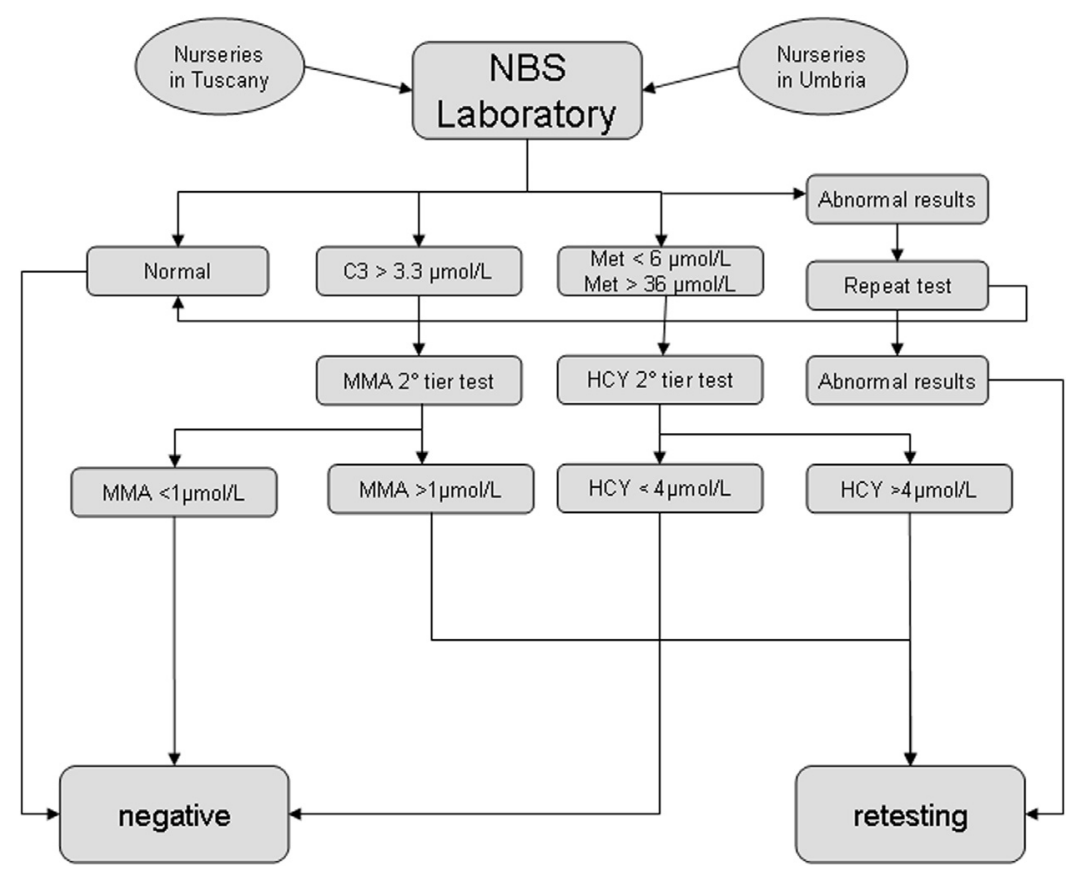

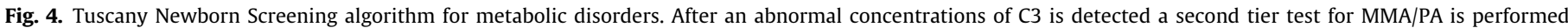

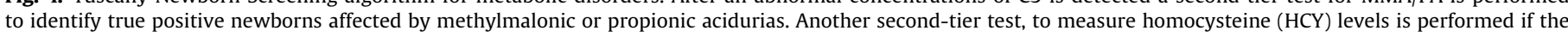

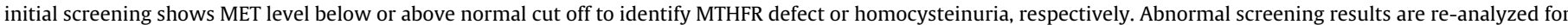
confirmation before requiring new specimen.

\section{Conclusions}

MS has been used in expanded NBS programs for over 20 years and it has been shown beneficial impacts on public health care compared to traditional programs. Current trends in NBS aimed at expanding testing panels covering a wide range of conditions. Research to include more tests in NBS have made huge steps forward in improving survival and in preventing long-term permanent damage in affected patients. However, the expansion of NBS raises some ethical implications relating to variability among states in conditions included, informed consent for storage and use of residual DBS, whether or not may be appropriate to identify carrier status or adult onset conditions.

Data collected from pilot studies can be used to create guidelines that can significantly help develop NBS programs and create opportunities.

NBS program is a complex process depending on a multidisciplinary team including pediatricians, IEM specialists, geneticists, dieticians as well as biologists and chemists with expertise in mass spectrometry. The collaboration of all these professionals has contributed to this success.

\section{Acknowledgments}

I thank Dr Sabrina Malvagia, Dr Silvia Funghini, Dr Elisa Giocaliere, Dr Daniela Ombrone and Dr Giulia Forni from the Newborn Screening, Biochemistry and Pharmacology Lab of Meyer children's University Hospital of Florence for constructive discussion, for typing the manuscript and for the art work.

\section{References}

[1] R. Guthrie, A. Susi, A simple phenylalanine method for detecting phenylketonuria in large populations of newborn infants, Pediatrics 32 (1963) 338-343.

[2] D.S. Millington, N. Kodo, D.L. Norwood, C.R. Roe, Tandem mass spectrometry: a new method for acylcarnitine profiling with potential for neonatal screening for inborn errors of metabolism, J. Inherit. Metab. Dis. 13 (1990) 321-324.
[3] G. la Marca, S. Malvagia, E. Pasquini, M. Innocenti, M.R. Fernandez, M.A. Donati, E. Zammarchi, The inclusion of succinylacetone as marker for tyrosinemia type I in expanded newborn screening programs, Rapid Commun. Mass Spectrom. 22 (2008) 812-818.

[4] C. Turgeon, M.J. Magera, P. Allard, S. Tortorelli, D. Gavrilov, D. Oglesbee, K. Raymond, P. Rinaldo, D. Matern, Combined newborn screening for succinylacetone, amino acids, and acylcarnitines in dried blood spots, Clin. Chem. 54 (2008) 657-664.

[5] C. Azzari, G. la Marca, M. Resti, Neonatal screening for severe combined immunodeficiency caused by an adenosine deaminase defect: a reliable and inexpensive method using tandem mass spectrometry, J. Allergy Clin. Immunol. 127 (2011) 1394-1399.

[6] G. la Marca, C. Canessa, E. Giocaliere, F. Romano, M. Duse, S. Malvagia, F. Lippi, S. Funghini, L. Bianchi, M.L. Della Bona, C. Valleriani, D. Ombrone, M. Moriondo, F. Villanelli, C. Speckmann, S. Adams, B.H. Gaspar, M. Hershfield, I. Santisteban, L. Fairbanks, G. Ragusa, M. Resti, M. de Martino, R. Guerrini, C. Azzari, Tandem mass spectrometry, but not T-cell receptor excision circle analysis, identifies newborns with late-onset adenosine deaminase deficiency, J. Allergy Clin. Immunol. 131 (2013) 1604-1610.

[7] C. Speckmann, C. Neumann, S. Borte, G. la Marca, J.O. Sass, E. Wiech, P. Fisch, K. Schwarz, B. Buchholz, M. Schlesier, K. Felgentreff, B. Grimbacher, I. Santisteban, P. Bali, M.S. Hershfield, S. Ehl, Delayed-onset adenosine deaminase deficiency: strategies for an early diagnosis, J. Allergy Clin. Immunol. 130 (2012) 991-994.

[8] G. la Marca, E. Giocaliere, S. Malvagia, S. Funghini, D. Ombrone, M.L. Della Bona, C. Canessa, F. Lippi, F. Romano, R. Guerrini, M. Resti, C. Azzari, The inclusion of ADA-SCID in expanded newborn screening by tandem mass spectrometry, J. Pharm. Biomed. Anal. 88 (2014) 201-206

[9] J.M.G. Wilson, G. Jungner, Principles and Practice of Screening for Disease, WHO, Geneva, 1968, Available from: http://www.who.int/bulletin/volumes/ 86/4/07-050112BP.pdf

[10] J.G. Loeber, P. Burgard, M.C. Cornel, T. Rigter, S.S. Weinreich, K. Rupp, G.F. Hoffmann, L. Vittozzi, Newborn screening programmes in Europe; arguments and efforts regarding harmonization. Part 1. From blood spot to screening result, J. Inherit. Metab. Dis. 35 (July (4)) (2012) 603-611.

[11] B. Wilcken, V. Wiley, Newborn screening, Pathology 40 (2008) 104-115.

[12] L.L. Wu, B.S. Sazali, N. Adeeb, B.A. Khalid, Congenital hypothyroid screening using cord blood TSH, Singapore Med. J. 40 (1999) 23-26.

[13] M. Abduljabbar, A. Al Shahri, A. Afifi, Is umbilical cord blood total thyroxin measurement effective in newborn screening for hypothyroidism? J. Med. Screen. 16 (2009) 119-123.

[14] J.D. Hardy, R. Zayed, I. Doss, G.S. Dhatt, Cord blood thyroxine and thyroid stimulating hormone screening for congenital hypothyroidism: how useful are they? J. Pediatr. Endocrinol. Metab. 21 (2008) 245-249.

[15] J.H. Walter, A. Patterson, J. Till, G.T. Besley, G. Fleming, M.J. Henderson, Bloodspot acylcarnitine and amino acid analysis in cord blood samples: efficacy and reference data from a large cohort study, J. Inherit. Metab. Dis. 32 (2009) 95-101. 
[16] C. Auray-Blais, D. Cyr, R. Drouin, Quebec neonatal mass urinary screening programme: from micromolecules to macromolecules, J. Inherit. Metab. Dis. 30 (2007) 515-521.

[17] M.L. Couce, D.E. Castiñeiras, M.D. Bóveda, A. Baña, J.A. Cocho, A.J. Iglesias, C. Colón, J.R. Alonso-Fernández, J.M. Fraga, Evaluation and long-term follow-up of infants with inborn errors of metabolism identified in an expanded screening programme, Mol. Genet. Metab. 104 (2011) 470-475.

[18] P. Rinaldo, S. Zafari, S. Tortorelli, D. Matern, Making the case for objective performance metrics in newborn screening by tandem mass spectrometry, Ment. Retard. Dev. Disabil. Res. Rev. 12 (2006) 255-261.

[19] G. la Marca, S. Malvagia, B. Casetta, E. Pasquini, M.A. Donati, E. Zammarchi, Progress in expanded newborn screening for metabolic conditions by LC-MS/MS in Tuscany: update on methods to reduce false tests, J. Inherit. Metab. Dis. 31 (2008) S395-S404.

[20] D.H. Chace, D.S. Millington, N. Terada, S.G. Kahler, C.R. Roe, L.F. Hofman, Rapid diagnosis of phenylketonuria by quantitative analysis for phenylalanine and tyrosine in neonatal blood spots by tandem mass spectrometry, Clin. Chem. 39 (1993) 66-71.

[21] A.L. Yergey, D.J. Liberato, D.S. Millington, Thermospray liquid chromatography/mass spectrometry for the analysis of L-carnitine and its short-chain acyl derivatives, Anal. Biochem. 139 (1984) 278-283.

[22] D.S. Millington, C.R. Roe, D.A. Maltby, Characterization of new diagnostic acylcarnitines in patients with beta-ketothiolase deficiency and glutaric aciduria type I using mass spectrometry, Biomed. Environ. Mass Spectrom. 14 (1987) 711-716.

[23] D. Millington, N. Kodo, N. Terada, D. Roe, D. Chace, The analysis of diagnostic markers of genetic disorders in human blood and urine using tandem mass spectrometry with liquid secondary ion mass spectrometry, Int. J. Mass Spectrom. Ion Process. 111 (1991) 211-228.

[24] D.H. Chace, Mass spectrometry in newborn and metabolic screening: historical perspective and future directions, J. Mass Spectrom. 44 (2009) 163-170.

[25] D.H. Chace, T. Lim, C.R. Hansen, V.R. De Jesus, W.H. Hannon, Improved MS/MS analysis of succinylacetone extracted from dried blood spots when combined with amino acids and acylcarnitine butyl esters, Clin. Chim. Acta 407 (2009) 6-9.

[26] G. la Marca, C. Canessa, E. Giocalier, F. Romano, S. Malvagia, S. Funghini, M. Moriondo, C. Valleriani, F. Lippi, D. Ombrone, M. Della Bona, C. Speckmann, S. Borte, N. Brodszki, A.R. Gennery, K. Weinacht, F. Celmeli, J. Pagel, M. de Martino, R. Guerrini, H. Wittkowski, I. Santisteban, P. Bali, M. Hershfield, L.D. Notarangelo, M. Resti, C. Azzari, Diagnosis of immunodeficiency caused by PNP defect using tandem mass spectrometry on dried blood spots, J. Allergy Clin. Immunol. (2014), http://dx.doi.org/10.1016/j.jaci.2014.01.040, pii S00916749(14)00265-6 [Epub ahead of print]

[27] A. Kwan, J.A. Church, M.J. Cowan, R. Agarwal, N. Kapoor, D.B. Kohn, D.B. Lewis, S.A. McGhee, T.B. Moore, E.R. Stiehm, M. Porteus, C.P. Aznar, R. Currier, F. Lorey, J.M. Puck, Newborn screening for severe combined immunodeficiency and T-cell lymphopenia in California: results of the first 2 years, J. Allergy Clin. Immunol. 132 (2013) 140-150.

[28] J. Mallott, A. Kwan, J. Church, D. Gonzalez-Espinosa, F. Lorey, L.F. Tang, U. Sunderam, S. Rana, R. Srinivasan, S.E. Brenner, J. Puck, Newborn screening for SCID identifies patients with ataxia telangiectasia, J. Clin. Immunol. 33 (2013) 540-549.

[29] Z. Spacil, H. Tatipaka, M. Barcenas, C.R. Scott, F. Turecek, M.H. Gelb, Highthroughput assay of 9 lysosomal enzymes for newborn screening, Clin. Chem. 59 (2013) 502-511.

[30] B.J. Wolfe, S. Blanchard, M. Sadilek, C.R. Scott, F. Turecek, M.H. Gelb, Tandem mass spectrometry for the direct assay of lysosomal enzymes in dried blood spots: application to screening newborns for mucopolysaccharidosis II (Hunter syndrome), Anal. Chem. 83 (2011) 1152-1156.

31] T. Khaliq, M. Sadilek, C.R. Scott, F. Turecek, M.H. Gelb, Tandem mass spectrometry for the direct assay of lysosomal enzymes in dried blood spots: application to screening newborns for mucopolysaccharidosis IVA, Clin. Chem. 57 (2011) $128-131$.

[32] T.A. Duffey, M. Sadilek, C.R. Scott, F. Turecek, M.H. Gelb, Tandem mass spectrometry for the direct assay of lysosomal enzymes in dried blood spots: application to screening newborns for mucopolysaccharidosis VI (Maroteaux-Lamy syndrome), Anal. Chem. 82 (2010) 9587-9591.

[33] S. Blanchard, M. Sadilek, C.R. Scott, F. Turecek, M.H. Gelb, Tandem mass spec trometry for the direct assay of lysosomal enzymes in dried blood spots: application to screening newborns for mucopolysaccharidosis I, Clin. Chem. 54 (2008) 2067-2070.

[34] M.H. Gelb, F. Turecek, C.R. Scott, N.A. Chamole, Direct multiplex assay of enzymes in dried blood spots by tandem mass spectrometry for the new born screening of lysosomal storage disorders, J. Inherit. Metab. Dis. 29 (2006) 397-404.

[35] D. Ombrone, S. Malvagia, S. Funghini, E. Giocaliere, M.L. Della Bona, G. Forni, A. De Luca, F. Villanelli, B. Casetta, R. Guerrini, G. la Marca, Screening of lysosomal storage disorders: application of the online trapping-and-cleanup liquid chromatography/mass spectrometry method for mucopolysaccharidosis I, Eur. J. Mass Spectrom. 19 (2013) 497-503.
[36] G. la Marca, B. Casetta, S. Malvagia, R. Guerrini, E. Zammarchi, New strategy for the screening of lysosomal storage disorders: the use of the online trapping-and-cleanup liquid chromatography/mass spectrometry, Anal. Chem. 81 (2009) 6113-6121.

[37] T.P. Mechtler, S. Stary, T.F. Metz, V.R. De Jesús, S. Greber-Platzer, A. Pollak, K.R Herkner, B. Streubel, D.C. Kasper, Neonatal screening for lysosomal storage disorders: feasibility and incidence from a nationwide study in Austria, Lancet 379 (2012) 335-341.

[38] X.K. Zhang, C.S. Elbin, W.L. Chuang, S.K. Cooper, C.A. Marashio, C. Beauregard J.M. Keutzer, Multiplex enzyme assay screening of dried blood spots for lysosomal storage disorders by using tandem mass spectrometry, Clin. Chem. 54 (2008) 1725-1728

[39] S. Malvagia, G. la Marca, B. Casetta, S. Gasperini, E. Pasquini, M.A. Donati, E. Zammarchi, Falsely elevated C4-carnitine as expression of glutamate formiminotransferase deficiency in tandem mass spectrometry newborn screening, J. Mass Spectrom. 41 (2006) 263-265

[40] S.C. Stadler, R. Polanetz, E.M. Maier, S.C. Heidenreich, B. Niederer, P.U. Mayerhofer, F. Lagler, H.G. Koch, R. Santer, J.M. Fletcher, E. Ranieri, A.M. Das, U. Spiekerkötter, K.O. Schwab, S. Pötzsch, I. Marquardt, J.B. Hennermann, I Knerr, S. Mercimek-Mahmutoglu, N. Kohlschmidt, B. Liebl, R. Fingerhut, B. Olgemöller, A.C. Muntau, A.A. Roscher, W. Röschinger, Newborn screening for 3-methylcrotonyl-CoA carboxylase deficiency: population heterogeneity of MCCA and MCCB mutations and impact on risk assessment, Hum. Mutat. 27 (2006) 748-759.

[41] O.A. Bodamer, G.F. Hoffmann, M. Lindner, Expanded newborn screening in Europe 2007, J. Inherit. Metab. Dis. 30 (2007) 439-444.

[42] S.C. Grünert, M. Stucki, R.J. Morscher, T. Suormala, C. Bürer, P. Burda, E. Christensen, C. Ficicioglu, J. Herwig, S. Kölker, D. Möslinger, E. Pasquini, R. Santer, K.O. Schwab, B. Wilcken, B. Fowler, W.W. Yue, M.R. Baumgartner, 3-methylcrotonylCoA carboxylase deficiency: clinical, biochemical, enzymatic and molecular studies in 88 individuals, Orphanet J. Rare Dis. 7 (2012) 31

[43] M. Nizon, C. Ottolenghi, V. Valayannopoulos, J.B. Arnoux, V. Barbier, F. Habarou, I. Desguerre, N. Boddaert, J.P. Bonnefont, C. Acquaviva, J.F. Benoist, D. Rabier G. Touati, P. de Lonlay, Long-term neurological outcome of a cohort of 80 patients with classical organic acidurias, Orphanet J. Rare Dis. 8 (2013) $148-160$

[44] E.S. Tan, V. Wiley, K. Carpenter, B. Wilcken, Non-ketotic hyperglycinemia is usually not detectable by tandem mass spectrometry newborn screening, Mol Genet. Metab. 90 (2007) 446-448.

[45] F. Ciani, E. Pasquini, A. Ciardetti, M.A. Donati, E. Zammarchi, Hyperglycinemia in clinical-laboratory practice, Pediatr. Med. Chir. 19 (1997) 109-112.

[46] D.H. Chace, W.H. Hannon, Clin. Chem. 56 (2010) 1653-1655.

[47] J. Calvin, S.L. Hogg, D. McShane, S.A. McAuley, R. Iles, R. Ross-Russell, F.M MacLean, M.E. Heeley, A.F. Heeley, Norfolk, Suffolk and Cambridgeshire paediatric cystic fibrosis network, Arch. Dis. Child. 97 (2012) 1043-1047.

[48] J.Y. Seo, H.D. Park, J.W. Kim, H.J. Oh, J.S. Yang, Y.S. Chang, W.S. Park, S.Y. Lee, Steroid profiling for congenital adrenal hyperplasia by tandem mass spectrometry as a second-tier test reduces follow-up burdens in a tertiary care hospital: a retrospective and prospective evaluation, J. Perinat. Med. 42 (2014) $121-127$

[49] O.Y. Al-Dirbashi, M.S. Rashed, M. Jacob, L.Y. Al-Ahaideb, M. Al-Amoudi, Z Rahbeeni, M.M. Al-Sayed, Z. Al-Hassnan, M. Al-Owain, H. Al-Zeidan, Biomed. Chromatogr. 22 (2008) 1181-1185.

[50] G. la Marca, S. Malvagia, S. Funghini, E. Pasquini, G. Moneti, R. Guerrini, E. Zammarchi, The successful inclusion of succinylacetone as a marker of tyrosinemia type I in Tuscany newborn screening program, Rapid Commun. Mass Spectrom. 23 (2009) 3891-3893.

[51] G. la Marca, S. Malvagia, E. Pasquini, M. Innocenti, M.A. Donati, E. Zammarchi, Rapid 2nd-tier test for measurement of 3-OH-propionic and methylmalonic acids on dried blood spots: reducing the false-positive rate for propionylcarnitine during expanded newborn screening by liquid chromatography-tandem mass spectrometry, Clin. Chem. 53 (2007) 1364-1369.

[52] T. Cloppenborg, N. Janzen, H. Wagner, U. Steuerwald, M. Peter, A. Das, Application of a second-tier newborn screening assay for C5 isoforms, JIMD Rep. (2013)

[53] X. Fu, Y.K. Xu, P. Chan, P.K. Pattengale, Simple, fast, and simultaneous detection of plasma total homocysteine, methylmalonic acid, methionine, and 2-methylcitric acid using liquid chromatography and mass spectrometry (LC/MS/MS), JIMD Rep. 10 (2013) 69-78.

[54] C. Wang, H. Zhu, W. Zhang. F. Song, Z. Liu, S. Liu, Second-tier test for quantification of underivatized amino acids in dry blood spot for metabolic diseases in newborn screening, Amino Acids 44 (2013) 661-671.

[55] A. Gucciardi, P. Pirillo, I.M. Di Gangi, M. Naturale, G. Giordano, A rapid UPLC-MS/MS method for simultaneous separation of 48 acylcarnitines in dried blood spots and plasma useful as a second-tier test for expanded newborn screening, Anal. Bioanal. Chem. 404 (2012) 741-751.

[56] A. Alodaib, K. Carpenter, V. Wiley, K. Sim, J. Christodoulou, B. Wilcken, An improved ultra performance liquid chromatography-tandem mass spectrometry method for the determination of alloisoleucine and branched chain amino acids in dried blood samples, Ann. Clin. Biochem. 48 (2011) 468-470. 